\title{
The Relation between Polymorphisms in Exon 5 and Exon 6 of GSTP1 Gene and the Risk of Lung Cancer in Iranian People
}

\author{
Gholamreza Shahsavari ${ }^{1}$, Ali Amiri², Masoud Shamaei ${ }^{3}$, Glavizh Adibhesami ${ }^{1 *}$, \\ Amirnader Emami Razavi ${ }^{4}$, Mehdi Birjandi ${ }^{5}$, Mihan Pourabdollah ${ }^{3}$
}

\begin{abstract}
Objective: The GSTP1 gene, which is located on chromosome 11q13, consists of 7 exons and 6 introns. There are two polymorphisms in GSTP1 that have been exposed to a transposition for codon 105 (Ile/Val) and 114 (Ala/Val) in exons 5 and 6, which have been studied previously in relation to lung cancer. Since the level of GSTP1 expression in lung tissues and other human epithelial tissues is high, GSTP1Val-105 polymorphism is recognized as a sensitive factor for tobacco-related cancers, especially lung cancer. Methods: One hundred and twenty tissue block samples of patients with lung cancers and 120 peripheral blood samples of the control group were obtained from two referral cancer centers in Tehran, Iran, from 2011 to 2016. Genomic DNA was extracted from tissue blocks and buffy coat of study cases to detect SNP of GSTP1 gene using Tetra-primer ARMS-PCR. Results: There was a notable correlation between the incidence of lung cancer and variant Val105 (P-value $=0.001 ; \mathrm{OR}=2 / 6 ; 95 \% \mathrm{CI}=1.49-4.53$ ) and $\mathrm{Ile} 105$ ( $\mathrm{P}$-value $=0.003 ; \mathrm{OR}=0.41 ; 95 \% \mathrm{CI}=0.23-0.73)$. The odds ratio for lung cancer in the homozygous Ile105/Ile105 genotype was 3.56 times higher than that of individual with heterozygous Ile105/Val105 (P-value $<0.001 ; \mathrm{OR}=3 / 56$; 95\% CI=1.826-6.934) genotype, that was statistically significant. Furthermore, the results showed that there was no significant correlation between Ala114/Val114 genotypes and lung cancer. The BC (P-value $=0.007 ; \mathrm{OR}=0.16 ; 95 \%$ $\mathrm{CI}=0.04-0.61)$ and $\mathrm{AA}(\mathrm{P}=0.001)$ genotypes were statistically significant ( $\mathrm{P}$-value $<0.05)$; and for those who had AA genotype, the odds ratio was almost six times higher than those with BC genotype. Conclusions: The study of GSTP1 polymorphisms indicated that unlike the polymorphism in exon 5, the GSTP1 exon 6 polymorphism correlated with the lung cancer risk in the select group of Iranian people. Likewise, the potential use of this genetic polymorphism as a lung cancer predictor is confirmed.
\end{abstract}

Keywords: Glutathione S-Transferase pi- Lung Neoplasms- Single-Nucleotide Polymorphism (SNP)- ARMS-PCR

Asian Pac J Cancer Prev, 20 (5), 1503-1509

\section{Introduction}

Environmental contamination with polycyclic aromatic hydrocarbons (PAHs) has become one of the major health concerns. It has been distinguished as a major cause of life threating diseases such as lung cancer. Studying the world's population exposed to PAHs inhalation has indicated that those who were exposed to these bioavailable sources were more susceptible to lung cancer than others (Rengarajan et al., 2015; Abdel-Shafy and Mansour, 2016).

As a developing country, Iran is profoundly exposed to environmental pollution caused by PAHs. Studies in Tehran (Karyab et al., 2013; Naddafi et al., 2017) and other large cities of Iran (Lübeck et al., 2016; Goudarzi et al., 2017) have confirmed that PAHs, which are abundant in smoke, contaminated air, and smoke from fossil fuels, are environmental pollutants. The human body has two protective mechanisms (i.e., the first and the second phases of antioxidant defense) to protect against these threatening compounds. In the first phase, the antioxidant defense is performed by the cytochrome P450 (CYP) enzymes. Furthermore, the defense in the second phase is done by the glutathione S-transferase (GSTs) enzymes and through conjugation of PAHs with glutathione GSH, which is the first stage of the mercapturic acid synthesis reaction that can prevent the damage in macromolecules (Mota et al., 2015; Peddireddy et al., 2016). GSTs (EC 2.5.1.18) have been identified as a superfamily of dopaminergic enzymes, which combine endogenous products derived from oxidative stress and electrophilic xenobiotics such as carcinogens, pesticides, drugs and bio-contaminating

${ }^{1}$ Department of Biochemistry and Genetics, ${ }^{2}$ Department of Pulmonary, ${ }^{5}$ Nutritional Health Research Center, Lorestan University of Medical Sciences, Khorramabad, ${ }^{3}$ Chronic Respiratory Diseases Research Center, National Research Institute of Tuberculosis and Lung Diseases (NRITLD), Shahid Beheshti University of Medical Sciences, ${ }^{4}$ Iran National Tumor Bank, Cancer Biology Research Center, Cancer Institute of Iran, Tehran University of Medical Sciences, Tehran, Iran. *For Correspondence: glavizh.adib@gmil.com 
materials targeted (Hayes et al., 2005).

Several studies investigated the polymorphism of this family of genes confirm that the combination of GSTT1, GSTM1, and GSTP1 genes increases the susceptibility to Glaucoma (Kazemi Safa et al., 2014; Safa et al., 2015) and various cancers such as lung (Sharma et al., 2015; Adibhesami et al., 2018), bladder (Yu et al., 2016), colorectal (Hezova et al., 2012), and head/neck cancers (Russo et al., 2013). GST $\pi$, also known as GSTP1, belongs to GSTs family with high expression in the lung, and it is positioned on chromosome 11q13. It is 2.8 kilobytes and consists of 7 exons and 6 introns (Sies, 1999; Hammond et al., 2001). There are two single-nucleotide polymorphisms (SNPs) in GSTP1 derived from amino acid substitutions, which are replaced by Ile 105 to Val105 in exon 5 and in codon 114 as substitution of Ala114 to Val114 in exon 6 in codon 105, contributing to lung cancer (Ketterer et al., 1992; Zatorska et al., 2003). SNPs changes in GSTP1 have been found in four different alleles, including $G S T P 1{ }^{*} A$, $G S T P 1 * B, G S T P 1{ }^{*} C$, and $G S T P 1{ }^{*} D$ ones (Board et al., 1989).

The most abundant GSTP $1^{*} A$ allele is wild type of this allele, which appears from the substitution of Adenine (A) with Guanine $(\mathrm{G})$ in the nucleotide of the $313+$ alleles (Ile105-Val114) GSTP ${ }^{*} B$ and GSTP $1{ }^{*} C$ (Val105-Ala114), and displacement of Cytosine (C) by Thymine (T) in the nucleotide position of the $341+G S T P 1 * D$ type allele (Ile105-Val114) (Hemmingsen et al., 2001; Sharma et al., 2014).

Although there are various studies on the frequency of GSTP1 genotype and its relation to lung cancer, this research tried to address this issue in developing countries such as Iran with increasing cumulative hazard of PAHs due to air pollution in many of its large cities. These findings can expand the horizon of our knowledge concerning the role of GSTP1 polymorphism through studying 105 (Ile/ $\mathrm{Val})$ and 114 (Ala/ $\mathrm{Val}$ ) codon transposition in exon 5 and exon 6 and evaluating the risk of lung cancer in a selected group of Iranian people.

\section{Materials and Methods}

\section{Patients and Tissue Specimens}

In this study, 120 samples of paraffin tissue blocks (FFPE) were prepared from two centers of National Bank of Iran in Imam Khomeini Hospital and Dr. Masih Daneshvari Hospital located in Tehran, Iran. Histopathologically being confirmed by at least two pathologists, the tissue block samples consisted of various types of lung cancer including non-small cell lung cancer (NSCLC), lung squamous cell carcinoma (LSCC), and lung adenocarcinoma (LAC). Moreover, there were other lung cancers, namely large cell carcinoma (LCC), mesothelioma, and bronchial carcinoids, which have been addressed in Table 2.

Regarding the clinical data which were obtained from the medical history of patients, therapeutic regimen had not been prescribed for any of the patients in the study. Exclusion criteria included suffering from acute or chronic inflammatory diseases in the last six months or having any other malignant cancers. In addition, 120 blood samples of healthy people without any metabolic or chronic disease were considered as the control group. Verbal or written informed consent was obtained from each of the participants before entering the study. The Ethics Committee of Lorestan University of Medical Sciences reviewed and approved the study protocol (Lums. rec.1394.1). This study was administered in accordance with the Declaration of Helsinki and its consequent revisions (Carlson et al., 2004).

\section{DNA Extraction and PCR Methodology}

The DNA extraction of tumorous and normal lung tissue samples, and the DNA extraction of the control group were performed based on the GeneAll ${ }^{\circledR}$ kit and the Cinna Gene DNA extraction kit protocol, respectively. The ARMS-PCR method was used for the diagnosis of Ile105 Val in the GSTP1 gene and recognition of techno-specific SNPs (Sharma et al., 2014). The primary ARMS-PCR was used in order to describe the Ala114 $\rightarrow$ Val114 genotype (Table 1) .

Two PCRs were performed for each DNA sample. PCRs were performed in $25 \mu$ reaction volume containing 50-200 ng of $1 \mathrm{mM}$ genomic DNA, $0.5 \mathrm{mM} \mathrm{MgCl}, 8$ $\mathrm{mM} \mathrm{H}_{2} \mathrm{O}, 12.5 \mu \mathrm{M}$ of PCR Master Mix each (Thermo Fisher Scientific), and forward primer and reverse primers A or B $(1.5 \mu \mathrm{M}$ each). PCR was performed with initial denaturation at $94^{\circ} \mathrm{C}$ for $5 \mathrm{~min}$, followed by 35 cycles of denaturation at $94^{\circ} \mathrm{C}$ for $1 \mathrm{~min}$, annealing at $62^{\circ} \mathrm{C}$ for 1 min, elongation at $72^{\circ} \mathrm{C}$ for $2 \mathrm{~min}$, and a final extension at $72^{\circ} \mathrm{C}$ for $7 \mathrm{~min}$. A $998 \mathrm{bp}$ fragment was amplified.

After PCR, the product was electrophoresed on 1\% gel and the PCR products were observed with Ala114 and Val114 bands, which were kept inoculated by the Alw26I enzyme at $37^{\circ} \mathrm{C}$ for 16 hours and then electrophoresed on $2 \%$ gel (Figures 1 and 2 ).

The results of the initial PCR determined the site of SNP position 114 of two alleles Ala114 and Val114, and the end of the Alw26I enzyme after PCR product revealed SNP position 105 of two Val105 and Ile105 alleles. Results on the observed fracture PCR products electrophoresis with 4 bands at positions $73,260,322$, and 343 , the singlenucleotide mutant defines the Ile105, the probability of each of the $\left(G S T P 1^{*} A\right.$ or $\left.G S T P 1 * D\right)$ alleles and in the presence of 5 bands at positions 73, 93, 250, 260, and 322 pairs represent the single-nucleotide mutation Val105, which was the probability of each of the $(G S T P 1 * B$ or $G S T P 1^{*} C$ ) alleles. In the 6-band observation at positions $73,93,250,260,322$, and 343 , the pair showed the status of the heterozygote Ile105/Val105.

\section{Statistical Analysis}

Data analyses were performed using SPSS (version 16; SPSS Inc., Chicago). Analyzing the appropriate ratios and indices and appropriate dispersion, Chi-square and independent t-test and multivariate logistic regression were used. Data were expressed as the mean \pm standard deviation (SD) and the differences were considered statistically significant if $p$-values were $<0.05$. This study was conducted using Hardy-Weinberg equilibrium that in this population showed no significant association with $\mathrm{P}>0.05$. 


\section{Results}

The demographic information of patients and that of the control group have been indicated in Table 2. The results revealed that unlike gender $(\mathrm{P}$-value $=0.19)$, two groups differed significantly in terms of mean age (P-value $=0.013)$ (Table 2) .

GSTP1 Ala/Val114 genotype and allele frequency have been indicated in Table 3. For those with Ala114/ Ala114 genotype, the odds ratio of lung cancer was $34 \%$ higher than that for the control group with Ala114/ Val114 heterozygote genotype $(\mathrm{P}$-value $=0.515 ; \mathrm{OR}=1 / 34$; $95 \% \mathrm{CI}=0.556-3.22$ ), although it was not statistically significant. The results also showed that for those who had the Ala114/Ala114 genotype, the odds ratio for lung cancer was $65 \%$ higher than that for control group with homozygous Val114/Val114 genotype $(\mathrm{P}$-value $=0.089$; $\mathrm{OR}=0.61 ; 95 \% \mathrm{CI}=0.34-1.08)$ (Table 3$)$.

The odds ratio of lung cancer for variant Val105 allele was 2.6 higher than that for the control group (P-value $=0.001 ; \mathrm{OR}=2 / 6 ; 95 \% \mathrm{CI}=1.49-4.53)$. The frequency of an Ile105 allele in lung cancer was approximately 2.45 -fold higher than that for control group ( $\mathrm{P}$-value $=0.003$; $\mathrm{OR}=0.41 ; 95 \% \mathrm{CI}=0.23-0.73$ ) (Table 4) .

Those presenting the Ile105/Val105 genotype with lung cancer had 3.56 times higher odds than the control group with heterozygous Ile105/Val105 genotype (P-value $<0.001 ; \mathrm{OR}=3 / 56 ; 95 \% \mathrm{CI}=1.83-6.93)$. Individuals with the genotype Ile105/Ile105 with lung cancer showed 1.75 times higher odds than the control group with heterozygous Val105/Val105 genotype $(\mathrm{P}$-value $=0.86$; $\mathrm{OR}=1.75 ; 95 \% \mathrm{CI}=0.92-3.34)$, that was not statistically significant (Table 5).

The GSTP1 BC genotype was statistically significant considering its p-value ( 0.007 ); and for those who had AA genotype, the odds ratio was almost six times higher than that of their GSTP1 BC genotype (P-value $=0.007$; $\mathrm{OR}=0.16 ; 95 \% \mathrm{CI}=0.04-0.61)$. The GSTP1 $A A$ genotype was statistically significant regarding p-value ( 0.001$)$ (Table 6).

In the next step, we used the multivariate logistic regression model to evaluate the effects of GSTP1 genotype on lung cancer while adjusting age and sex (Table 7). Assuming that other variables are stable, the odds of having Val105- allele was 2.22 times higher than those with Val105+ allele, which was statistically significant $(\mathrm{P}$-value $=0.015 ; \mathrm{OR}=2.22 ; 95 \%$ $\mathrm{CI}=1.16-4.23$ ). Furthermore, the odds of lung cancer in women were 2 times higher than that of men. This increase was statistically significant $(\mathrm{P}$-value $=0.02, \mathrm{OR}=0.5$; $95 \% \mathrm{CI}=0.28-0.9$ ). Considering the effect of age and sex using logistic regression model, there was no significant difference in odds ratios of Ile105 with the risk of lung cancer (Table 7).

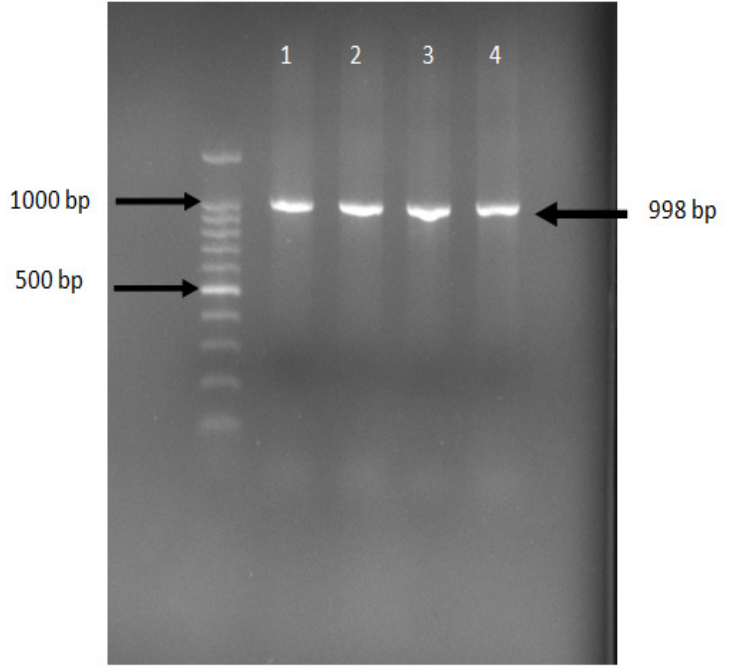

Figure 1. Electrophoresis of the GSTP1 Genotype Ala114 and Val114. Lines 1 and 2 are associated with genotype Ala114 and lines 3 and 4 correlated to genotype Val114 that are observed in all specimens

\section{Discussion}

GSTP1 plays an important role in the detoxification process, which protecting cells form inhaled carcinogens such as benzo(a)pyrene and PAHs. The results of the present study indicated a significant difference in the frequency of GSTP1 Ile/Val genotypes in exon 5; whereas, there was no significant difference in GSTP1 Ala/Val genotypes in exon 6 with the risk of lung cancer. Moreover, we found that GSTP1 BC and $A A$ increased in lung cancer. Studying GSTP1 polymorphism also showed a significant

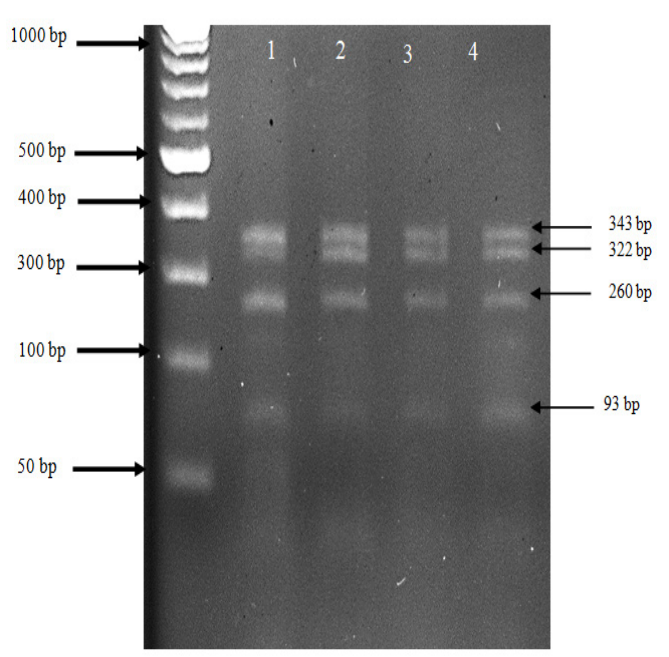

Figure 2. Electrophoresis Results after Incubation with the Alw26I Enzyme. In the presence of 4 bands at positions $73,260,322$, and 343 pairs the singlenucleotide mutant defines the Ile105, the probability of each of the (GSTP1*A or GSTP1*D) alleles (Lines 1, 2, 3 , and 4).

Table 1. Primer Sequences

\begin{tabular}{llccc}
\hline Polymorphism & Primer & Annealing & Product PCR & Reference \\
\hline GSTP1 forward & 5'- ACC CCA GGG CTC TAT GGG AA-3' & & 998 bp & (Sharma et al., 2014) \\
GSTP Ala reverse & 5'- TCA CAT CAT CCT TGC CGG-3' & 62 C & & \\
GSTP Val reverse & 5'- TCA CAT CAT CCT TGC CGA-3' & $60 \mathrm{C}$ & & \\
\hline
\end{tabular}


Table 2. Demographic Data of the Study Population

\begin{tabular}{lccc}
\hline Study group & Control group & Lung cancer group & P-value \\
\hline Number of subjects & 120 & 120 & - \\
Sex & & & 0.019 \\
$\quad$ Men, n (\%) & $90(75.0 \%)$ & $72(60.0 \%)$ & $48(40.0 \%)$ \\
$\quad$ Women, n (\%) & $30(25.0 \%)$ & & \\
Lung Cancer Type & & $19(15.8 \%)$ & \\
$\quad$ Non-Small Cell Lung Cancer (NSCLC) & & $39(32.5 \%)$ & \\
$\quad$ Lung Adenocarcinoma (LAC) & $36(30 \%)$ & 0.13 \\
$\quad$ Lung Squamous Cell Carcinoma (LSCC) & & $26(21.7 \%)$ & \\
$\quad$ Other Types & $55.2167 \pm 12.63660$ & $54.4583 \pm 9.98730$ & \\
Age (Mean year \pm SD) & &
\end{tabular}

Table 3. Genotype Distribution and Risk Lung Cancer Associated with GSTP1 Ala/Val114 genotype and Allele Frequency

\begin{tabular}{lccccc}
\hline Genotype & Control Group & Lung Cancer Group & OR & $95 \%$ CI & P-Value \\
\hline Ala114/Ala114 & $11(9.2 \%)$ & $19(15.8 \%)$ & Reference & - & 0.071 \\
Ala114/Val114 & $78(65 \%)$ & $61(50.8 \%)$ & 1.34 & $0.556-3.22$ & 0.515 \\
Val114/Val114 & $31(25.8 \%)$ & $40(33.3 \%)$ & 0.61 & $0.34-1.08$ & 0.089 \\
Total & $120(100 \%)$ & $120(100 \%)$ & - & & \\
\hline
\end{tabular}

Table 4. Genotype Distribution and Risk Lung Cancer Associated with GSTP1 Ile105 and Val105 Allele Frequency

\begin{tabular}{lccccc}
\hline Allele & Control group $(\mathrm{n}=120)$ & Lung cancer group $(\mathrm{n}=120)$ & OR & $95 \%$ CI & P-value \\
\hline Val105 & & & 2.6 & $1.49-4.53$ & 0.001 \\
Present, n (\%) & $92(76.7 \%)$ & $67(55.8 \%)$ & & \\
n (\%) & $28(23.3 \%)$ & $53(44.2 \%)$ & & \\
Ile105 & & & & \\
Present, n (\%) & $73(60.8 \%)$ & $95(79.2 \%)$ & & & \\
n (\%) & $47(39.2 \%)$ & $25(20.8 \%)$ & & \\
\hline
\end{tabular}

relationship between GSTP1 Ile/Val genotype and lung cancer in exon 5; while, no significant relation was found between GSTP1 Ala/Val genotypes with exon 6 and lung cancer. Considering the different types of alleles, this polymorphism in GSTP1 BC and $A A$ showed a significant relation with lung cancer.

Epidemiological studies have confirmed that those who express different types of GSTP1 alleles are less susceptible to various types of carcinogenic agents (Josephy, 2010; Andreoli and Sprovieri, 2017). Recent studies have reported the relation between GSTP1 Val105 polymorphism and other types of cancers, including prostate (Wei et al., 2013), breast (Louie et al., 2016), and bladder cancers (Yu et al., 2016).

We found no relationship between the homozygote genotype Ala114/Ala114 (P-value=0.071), Ala114/Val114
$(\mathrm{P}$-value $=0.515)$, and Val114/Val114 $(\mathrm{P}$-value $=0.089)$ and the risk of lung cancer. In a nutshell, no significant difference was observed in GSTP1 Ala /Val genotype in exon 6 with the risk of lung cancer. On the other hand, a significant correlation between SNP genotype exon 6 Ala114/Val114 and the risk of lung cancer was reported previously (Yan et al., 2016). Our findings; however, were in line with those reported by Wang et al., (2003), Lakhdar et al.,(2010), and Yang et al., (2004).

In this study, those who had the Val105 allele with lung cancer had a 2.6-fold higher odds than healthy individuals, which was statistically significant $(\mathrm{P}$-value $=0.001)$. Furthermore, there was a significant correlation between the frequency of the alleles Ile105 (P-value=0.003) in lung cancer compared to the control group.

The lowest proportion of the Val105 allele exists in a

Table 5. Genotype Distribution and Risk Lung Cancer Associated with GSTP1 Ile/Val105 Genotype Frequency

\begin{tabular}{lccccc}
\hline Genotype & Control Group & Lung Cancer Group & OR & $95 \%$ CI & P-Value \\
\hline Ile105/Ile105 & $28(23.3 \%)$ & $53(42.2 \%)$ & Reference & - & 0.001 \\
Ile105/Val105 & $45(37.5 \%)$ & $42(35 \%)$ & 3.56 & $1.83-6.93$ & $<0.001$ \\
Val105/Val105 & $47(39.2 \%)$ & $25(20.8 \%)$ & 1.75 & $0.92-3.34$ & 0.86 \\
Total & $120(100 \%)$ & $120(100 \%)$ & - & & \\
\hline
\end{tabular}


DOI:10.31557/APJCP.2019.20.5.1503

The Relation between Polymorphisms in Exon 5 and Exon 6 of GSTP1 Gene and the Risk of Lung Cancer

Table 6. Genotype Distribution and Risk Lung Cancer Associated with GSTP1 Genotype and Allele Frequency

\begin{tabular}{lccccc}
\hline Allele & Control Group & Lung Cancer Group & OR & $95 \%$ CI & P-Value \\
\hline AA & $5(4.2 \%)$ & $8(6.7 \%)$ & Reference & - & 0.001 \\
AB & $5(4.2 \%)$ & $5(4.2 \%)$ & 0.63 & $0.12-3.32$ & 0.56 \\
AC & $19(15.8 \%)$ & $20(16.7 \%)$ & 0.66 & $0.18-2.37$ & 0.52 \\
AD & $20(16.7 \%)$ & $27(22.5 \%)$ & 0.84 & $0.24-2.97$ & 0.79 \\
BB & $2(1.7 \%)$ & $6(5 \%)$ & 1.88 & $0.27-13.2$ & 0.53 \\
BC & $38(31.7 \%)$ & $10(8.3 \%)$ & 0.16 & $0.04-0.61$ & 0.007 \\
BD & $1(0.8 \%)$ & $3(2.5 \%)$ & 1.88 & $0.15-23.37$ & 0.63 \\
CC & $7(5.8 \%)$ & $9(7.5 \%)$ & 0.81 & $0.18-3.57$ & 0.77 \\
CD & $20(16.7 \%)$ & $13(10.8 \%)$ & 0.41 & $0.11-1.52$ & 0.18 \\
DD & $3(2.5 \%)$ & $19(15.8 \%)$ & 3.96 & $0.76-20.67$ & 0.103 \\
Total & $120(100 \%)$ & $120(100 \%)$ & - & & \\
\hline
\end{tabular}

Table 7. The Effect of Val 105 Allele, Ile105 Allele, Adjusting Age and Sex Genotypes, on Lung Cancer Using Multivariate Logistic Regression Model

\begin{tabular}{lcccc}
\hline Variable & Reference & OR & $95 \%$ CI & P-Value \\
\hline Age & & 0.99 & $0.97-1.018$ & 0.609 \\
$\begin{array}{l}\text { Sex } \\
\text { Men }\end{array}$ & Reference & 0.5 & $0.28-0.9$ & 0.02 \\
$\begin{array}{l}\text { Women } \\
\text { Val105+ }\end{array}$ & Reference & 2.22 & $1.16-4.23$ & 0.015 \\
Val105 - & & & & \\
Ile105+ & Reference & 0.61 & $0.31-1.19$ & 0.15 \\
Ile105 - & & & & \\
\hline
\end{tabular}

number of Asians in the Caucasus. The complete deletion of homozygous mutations of the Val105/Val105 genotype was also stated in a Japanese study (Kiyohara et al., 2002; Bull et al., 2009). Like this study, Garte et al., found that the Val/Val genotype was seldom showdown and there were less than 5\% among the Caucasus (Garte et al., 2001).

Moreover, for those who had the heterozygous Val105/Val105 genotype (CI=0.92-3.34), considering the $\mathrm{P}$-value of 0.86 , this increase did not statistically affect the risk of lung cancer. Individuals with Val105/Val105 polymorphism genotype of hepatocellular cancer had the chance for a better life ( $\mathrm{Li}$ et al., 2012). However, this genotype is barely related to essential basal cell epitheliums (Ramachandran et al., 2000) and breast cancer (Zhang et al., 2011).

In this study, the results indicated that the Ile105/Ile105 homozygote genotype implied a statistically significant effect $(\mathrm{P}-\mathrm{value}=0.001)$ for the risk of lung cancer. In addition, we observed a significant relation between GSTP1 Ile/Val genotype in exon 5 and the risk of lung cancer. Moreover, those with the heterozygous Ile105/ Val105 genotype, the odds ratio for lung cancer was 3.36 times higher than that for the control group in this study. Another study revealed that the genotype of the Ile105/ Ile105 and Ile105/Val105 genotypes, which have a certain variance in Asians but not in Africans, Europeans, and Indians, were presented (Mishra et al., 2004; Polimanti et al., 2011). The stability of this form of the GSTP1 enzyme is 2-3 times less than that of the Ile 105 polymorphism form (Hengstler et al., 1998) and may be due to high level of additional DNA combinations (Ramachandran et al., 2000). In another study by Li et al., (2015) in China, a significant correlation between GSTP1 polymorphism and lung cancer in exon 5 in the Ile105/Val105 and Val105/ Val105 genotypes was reported. In a study carried out by Uddin et al., (2014) all three GSTP1 Ile105Val genotypes were recognized as risk factors for lung cancer.

We found that GSTP1 BC $(\mathrm{P}=0.007)$ decreased in patients with lung cancer. In another study conducted by Anja Hemmingsen et al. with a similar method concerning the link between GSTP1 alleles and asthma phenotypes, the researchers designated that ARMS assay, atopic asthmatic and Nonatopic non-asthmatic persons had the GSTP1 BD, CD, or DD genotypes. GSTP1 BC was significantly related to the reduction of the risk for atopy (P-value=0.031) (Hammond et al., 2001).

Abdel-Alim et al., (2007) studied fifty asthmatic children and identified GSTP1 genotypes indicated that GSTP1 BB accounts for practically a threefold lower risk of asthma than did GSTP1 AA. Anita Sharma et al., (2014) examined the occurrences of two polymorphisms in exon 5 and exon 6 of GSTP1 gene in 500 healthy individuals since Delhi was investigated by PCR-RFLP.

This study suffers from some restrictions, including the fact that the evaluation of GSTP1 polymorphism has been accompanied with other cancer-associated GST polymorphisms. With regard to the impact of these polymorphisms, they can be evaluated either alone or in combination with other polymorphisms. Regarding the effect of PAHs compounds on lung cancer, a geographical assessment of the presence of this substance in target population should be considered. This polymorphism can be studied in other ways, i.e. measuring the expression of selected genes, measuring its performance against an antioxidant agent, and comparing various cancer-causing compounds.

In conclusion, investigating two gene polymorphisms related to GSTP1, This study confirmed that there was no significant relation between the risk of lung cancer and selected SNPs in exon 5; wherein, there was a significant relation between lung cancer and selected alleles, including Ile105 and Val105 as well as Ile105/Val105 and Ile105/Ile105 genotypes. Considering all the diverse 
alleles of GSTP1, the GSTP $1 * B$ allele only displayed a significant relation with lung cancer, which is probably due to the influence of SNP on reduction of the activity of this enzyme.

\section{Funding Statement}

The funders had no role in study design, data collection and analysis, decision to publish, or preparation of the manuscript.

\section{Statement conflict of Interest}

All authors of this article have no conflict of interest with regard to the present research and its results.

\section{Acknowledgements}

The authors would like to thank all the people who helped with the study or preparation of the paper, including those who provided technical assistance to the authors. We also gratefully acknowledge the financial support for this work that was provided by Lorestan University of Medical Sciences.

\section{References}

Abdel-Alim SM, El-Masry MM, Aziz M, et al (2007). Association of glutathione-S-transferase P1 genotypes with susceptibility to bronchial asthma in children. Arch Med Sci, 3, 200.

Abdel-Shafy HI, Mansour MSM (2016). A review on polycyclic aromatic hydrocarbons: Source, environmental impact, effect on human health and remediation. Egypt J Petrol, 25, 107-23.

Adibhesami G, Shahsavari GR, Amiri A, et al (2018). Glutathione S-transferase M1 (GSTM1) and T1 (GSTT1) Polymorphisms and lung cancer risk among a select group of Iranian people. Asian Pac J Cancer Prev, 19, 2921-7.

Andreoli V, Sprovieri F (2017). Genetic aspects of susceptibility to Mercury toxicity: An overview. Int J Environ Res Public Health, 14, 93.

Board PG, Webb GC, Coggan M (1989). Isolation of a cDNA clone and localization of the human glutathione S-transferase 3 genes to chromosome bands 11q13 and 12q13-14. Ann Hum Genet, 53, 205-13.

Bull LM, White DL, Bray M, et al (2009). Phase I and II enzyme polymorphisms as risk factors for Barrett's esophagus and esophageal adenocarcinoma: a systematic review and meta-analysis. Dis Esophagus, 22, 571-87.

Carlson RV, Boyd KM, Webb DJ (2004). The revision of the Declaration of Helsinki: past, present and future. Br J Clin Pharmacol, 57, 695-713.

Garte S, Gaspari L, Alexandrie AK, et al (2001). Metabolic gene polymorphism frequencies in control populations. Cancer Epidemiol Biomarkers Prev, 10, 1239-48.

Goudarzi G, Idani E, Alavi N, et al (2017). Association of polycyclic aromatic hydrocarbons of the outdoor air in Ahvaz, southwest Iran during warm-cold season. Toxin Rev, 36, 282-9.

Hammond CL, Lee TK, Ballatori N (2001). Novel roles for glutathione in gene expression, cell death, and membrane transport of organic solutes. J Hepatol, 34, 946-54.

Hayes JD, Flanagan JU, Jowsey IR (2005). Glutathione Transferases. Annu Rev Pharmacol Toxicol, 45, 51-88.

Hemmingsen A, Fryer AA, Hepple M, et al (2001). Simultaneous identification of GSTP1 Ile105 $\rightarrow$ Val105 and Ala114 $\rightarrow$ Val114 substitutions using an amplification refractory mutation systempolymerase chain reactionassay: studies in patients with asthma. Respir Res, 2, 255-60.

Hengstler JG, Arand M, Herrero ME, et al (1998). Polymorphisms of N-acetyltransferases, glutathione S-transferases, microsomal epoxide hydrolase and sulfotransferases: influence on cancer susceptibility. Recent Results Cancer Res, 154, 47-85.

Hezova R, Bienertova-Vasku J, Sachlova M, et al (2012). Common polymorphisms in GSTM1, GSTT1, GSTP1, GSTA1 and susceptibility to colorectal cancer in the Central European population. Eur J Med Res, 17, 17.

Josephy PD (2010). Genetic variations in human Glutathione Transferase enzymes: Significance for pharmacology and toxicology. Hum Genomics Proteomics, 2010, 876940.

Karyab H, Yunesian M, Nasseri S, et al (2013). Polycyclic Aromatic Hydrocarbons in drinking water of Tehran, Iran. J Environ Health Sci Eng, 11, 25.

Kazemi Safa F, Shahsavari G, Zare Abyaneh R (2014). Glutathione s-transferase M1 and T1 genetic polymorphisms in Iranian patients with glaucoma. Iran J Basic Med Sci, 17, 332-6.

Ketterer B, Harris JM, Talaska G, et al (1992). The human glutathione $\mathrm{S}$-transferase supergene family, its polymorphism, and its effects on susceptibility to lung cancer. Environ Health Perspect, 98, 87-94.

Kiyohara C, Shirakawa T, Hopkin JM (2002). Genetic polymorphism of enzymes involved in xenobiotic metabolism and the risk of lung cancer. Environ Health Prev Med, 7, 47-59.

Lakhdar R, Denden S, Knani J, et al (2010). Relationship between glutathione S-transferase P1 polymorphisms and chronic obstructive pulmonary disease in a Tunisian population. Genet Mol Res, 9, 897-907.

Li CG, Zhao ZM, Hu MG, et al (2012). Predictive role of glutathione-S-transferase gene polymorphisms in risk and prognosis of hepatocellular carcinoma. Asian Pac J Cancer Prev, 13, 3247-52.

Li XM, Yu XW, Yuan Y, et al (2015). Glutathione S-transferase $\mathrm{P} 1$, gene-gene interaction, and lung cancer susceptibility in the Chinese population: An updated meta-analysis and review. J Cancer Res Ther, 11, 565-70.

Louie SM, Grossman EA, Crawford LA, et al (2016). GSTP1 is a driver of Triple-Negative breast cancer cell metabolism and pathogenicity. Cell Chem Biol, 23, 567-78.

Lübeck JS, Poulsen KG, Knudsen SB, et al (2016). Source apportionment of polycyclic aromatic hydrocarbons (PAHs) in sediments from Khuzestan province, Iran. Mar Pollut Bull, 110, 584-90.

Mishra DK, Kumar A, Srivastava DS, et al (2004). Allelic variation of GSTT1, GSTM1 and GSTP1 genes in North Indian population. Asian Pac J Cancer Prev, 5, 362-5.

Mota P, Silva HC, Soares MJ, et al (2015). Genetic polymorphisms of phase I and phase II metabolic enzymes as modulators of lung cancer susceptibility. J Cancer Res Clin Oncol, 141, 851-60.

Naddafi K, Yunesian M, Faridi S, et al (2017). Source identification of PM10-bound Polycyclic Aromatic Hydrocarbons (PAHs) of Tehran ambient air in year 2013. IJHE, 10, 25-36.

Peddireddy V, Badabagni SP, Gundimeda SD, et al (2016). Association of CYP1A1, GSTM1 and GSTT1 gene polymorphisms with risk of non-small cell lung cancer in Andhra Pradesh region of South India. Eur J Med Res, 21, $1-14$.

Polimanti R, Piacentini S, De Angelis F, et al (2011). Human GST Loci as markers of evolutionary forces: $G S T O 1{ }^{*} E 155 \mathrm{del}$ 
and $G S T O{ }^{*} E 208 K$ Polymorphisms may be under natural selection induced by environmental Arsenic. Dis Markers, 31, 231-9.

Ramachandran S, Hoban PR, Ichii-Jones F, et al (2000). Glutathione S-transferase GSTP1 and cyclin D1 genotypes: association with numbers of basal cell carcinomas in a patient subgroup at high-risk of multiple tumours. Pharmacogenetics, 10, 545-56.

Rengarajan T, Rajendran P, Nandakumar N, et al (2015). Exposure to polycyclic aromatic hydrocarbons with special focus on cancer. Asian Pac J Cancer Prev, 5, 182-9.

Russo A, Francelin PR, Galbiatti AL, et al (2013). Association between GSTP1, GSTM1 and GSTT1 polymorphisms involved in xenobiotic metabolism and head and neck cancer development. Mol Biol Rep, 40, 4181-8.

Safa FK, Shahsavari G, Miraftabi A (2015). Is the GSTMI null polymorphism a risk factor for primary angle-closure glaucoma among Iranian population?. Acta Med Iran, 53, $112-6$.

Sharma A, Pandey A, Sharma S, et al (2014). Genetic polymorphism of glutathione S-transferase P1 (GSTP1) in Delhi population and comparison with other global populations(). Meta Gene, 2, 134-42.

Sharma N, Singh A, Singh N, et al (2015). Genetic polymorphisms in $<e m>G S T M 1</ e m>$, $<e m>G S T T 1<1$ $e m>$ and $<e m>G S T P 1</ e m>$ genes and risk of lung cancer in a North Indian population. Cancer Epidemiol, 39, 947-55.

Sies H (1999). Glutathione and its role in cellular functions. Free Radic Biol Med, 27, 916-21.

Uddin MMN, Ahmed MU, Islam MS, et al (2014). Genetic polymorphisms of GSTM1, GSTP1 and GSTT1 genes and lung cancer susceptibility in the Bangladeshi population. Asian Pac J Cancer Prev, 4, 982-9.

Wang Y, Spitz MR, Schabath MB, et al (2003). Association between glutathione S-transferase $\mathrm{p} 1$ polymorphisms and lung cancer risk in Caucasians: a case-control study. Lung Cancer, 40, 25-32.

Wei B, Zhou Y, Xu Z, et al (2013). GSTP1 Ile105Val Polymorphism and Prostate Cancer Risk: Evidence from a Meta-Analysis. PLoS One, 8, e71640.

Yan F, Wang R, Geng L (2016). The $341 C / T$ polymorphism in the GSTP1 gene and lung cancer risk: a meta-analysis. Genet Mol Res, 15, 72-81.

Yang P, Bamlet WR, Ebbert JO, et al (2004). Glutathione pathway genes and lung cancer risk in young and old populations. Carcinogenesis, 25, 1935-44.

Yu Y, Li X, Liang C, et al (2016). The relationship between GSTA1, GSTM1, GSTP1, and GSTT1 genetic polymorphisms and bladder cancer susceptibility: A meta-analysis. Medicine (Baltimore), 95, e4900.

Zatorska A, Maszewski J, Jozwiak Z (2003). Changes in GSH-antioxidant system induced by daunorubicin in human normal and diabetic fibroblasts. Acta Biochim Pol, 50, 825-36.

Zhang BL, Sun T, Zhang BN, et al (2011). Polymorphisms of GSTP1 is associated with differences of chemotherapy response and toxicity in breast cancer. Chin Med J (Engl), 124, 199-204.

\section{(ब)}

This work is licensed under a Creative Commons AttributionNon Commercial 4.0 International License. 